\title{
MODEL FISIK ARAH ALIRAN GELOMBANG TSUNAMI DI DAERAH PURUS DAN ULAK KARANG PADANG
}

\author{
Darwizal Daoed $^{1}$, Muhamad Dwiko Febriansyah ${ }^{2}$, dan Masril Syukur ${ }^{3}$
}

\begin{abstract}
ABSTRAK
Gelombang besar atau tsunami merupakan gelombang yang dibangkitkan secara tektonik akibat pergeseran lempeng di laut. Dampaknya sangat besar bila gelombang ini merambat ke pantai, sebagai contoh peristiwa di Aceh dan Papua. Hal yang serupa ada kemungkinan terjadi di Sumatera, karena daerah ini mempunyai sesar di laut dan di daratan. Upaya mengurangi dampaknya ke pantai, perlu dilakukan, salah satunya simulasi secara fisik untuk dapat memprediksi dan melihat seberapa jauh dampak gelombang besar (tsunami) pada suatu lokasi. Secara teoritis sudah ada prediksi para ahli, tetapi tidak mencerminkan yang sesungguhnya. Dimana faktor karakteristik pantai, kedalaman laut, serta muara sungai sangat dominan mempengaruhi perilaku gelombang ke pantai. Pada tahap pertama lokasi daerah Purus dan Ulak Karang sekitarnya sebagai objek penelitian. Model dibuat dengan meniru bentuk asli dilapangan dengan melakukan beberapa penyederhanaan. Simulasi ombak (gelombang) dan banjir dilakukan dengan menumpahkan air dengan debit tertentu dan ketinggian tertentu (minimum tiga variasi masing-masingnya). Selanjutnya diamati dampak yang terjadi pada daerah daratan dengan mengukur kedalaman serta luasnya genangan (inundation). Dari penelitian ini diperoleh pada daerah Purus, yaitu jalan Raden Saleh (jalur evakuasi) tidak aman untuk dilewati pada simulasi gelombang sedang dan besar. Dimana aliran air relatif lebih cepat dibanding daerah lainnya. Begitu pula untuk daerah dekat drainase/sungai aliran semakin cepat mengalir dan kedalaman lebih tinggi.Jarak tempuh dari pinggir ke daerah aman harus lebih kecil dari 20 menit dengan kecepatan lebih besar dari $5 \mathrm{~km} / \mathrm{jam}$. Dari semua perlakuan daerah aman berada $2,5 \mathrm{~km}$ dari pantai. Untuk mengurangi risiko terhadap bencana, maka perlu dilakukan kajian lanjutan terhadap tata letak bangunan, kanal, maupun breakwater sepanjang pantai serta kombinasinya.
\end{abstract}

Kata kunci : model, aliran, genangan, tsunami,pantai, Padang

\section{PENDAHULUAN}

Pulau Sumatera yang membentang dari Utara hingga Selatan merupakan pulau yang memiliki beberapa sesar (patahan). Sesar tersebut melalui daratan, yakni sekitar Bukit Barisan dan di lautan dekat kepulauan Mentawai. Dua sesar ini sangat berpotensi untuk menjadikan goncangan atau disebut gempa (earthquake) yang akan memberikan dampak baik pada daratan maupun di laut. Untuk kasus di laut dapat saja menimbulkan gelombang besar atau dikenal dengan gelombang tsunami.

Gelombang besar dapat saja terjadi akibat gempa tektonik maupun akibat perubahan musim yaitu pergerakan udara yang dikenal dengan angin (fet). Yang terakhir ini dapat juga menyebabkan gelombang, akan tetapi tidak sebesar akibat gempa. Semua itu sangat memberikan risiko banjir

\footnotetext{
${ }^{I}$ StafPengajar Jurusan Teknik Sipil Fakultas Teknik Universitas Andalas e-mail:darwizaldaoed@ft.unand.ac.id

${ }^{2}$ Mahasiswa Pascasarjana Jurusan Teknik Sipil Fakultas Teknik Universitas Andalas.

${ }^{3}$ StafPengajarJurusanTeknikSipilFakultasTeknikUniversitasAndalas.
} 
(rob) atau pasang untuk daerah pantai (darat), sehingga daerah pinggir pantai sering mengalaminya. Dampak banjir atau genangan ini dapat secara berangsur-angsur seperti air pasang, maupun secara cepat, yakni dengan pukulan massa air yang bergerak dengan kecepatan tertentu.

Gelombang yang sering terjadi di laut yang disebut dengan ombak (wave) adalah akibat angin (fet). Ombak bentuk ini mempunyai tinggi gelombang berkisar antara $0,5-3,0 \mathrm{~m}$ dan kadangkala lebih dari 3,0 m. Hempasan ombak ke pantai dapat menyebabkan terkikisnya (erosi) pantai, sehingga pengaruhnya secara fisik daratan akan mundur dan sebaliknya lautan akan maju.

Fenomena ini dapat dilihat pada sepanjang pantai Padang.Dimana sekitar tahun 1970 di daerah pantai Olo Ladang terdapat Tempat Pekuburan Umum (TPU), yang mana saat ini kuburan tersebut telah habis terkikis. Dapat diperkirakan, bahwa laut telah maju lebih kurang 10 - 25 m dalam kurun waktu 44 tahun.

Selanjutnya untuk kasus gelombang besar (tsunami) akibatnya tentu akan menyebabkan banjir maupun pukulan gelombang yang jauh lebih besar ke pantai. Dimana gelombang ini dapat mencapai lebih dari $10 \mathrm{~m}$ dengan kecepatan di pusatnya $100-150 \mathrm{~km} / \mathrm{jam}$ dan di pantai sekitar 30 $\mathrm{km} / \mathrm{jam}$.Tentu dampak yang ditimbulkannyapun jauh lebih besar dari gelombang biasa.Sebagai gambaran gelombang yang terjadi di Aceh akhir tahun 2004 dengan korban harta dan jiwa yang cukup besar.

Berangkat dari fenomena tersebut perlu dilakukan pengkajian dan penelitian untuk dapat memberikan solusi agar risiko terhadap bencana gelombang dapat dikurangi khususnya di sepanjang pantai. Pada penelitian ini difokuskan pada daerah pantai kota Padang, yang memiliki pantai dengan kemiringan cukup besar (curam) dan daerah hunian berupa dataran yang cukup sempit sebagai pusat kegiatan (kawasan bisnis), serta pada daerah Timur dikelilingi oleh Bukit Barisan yang mempunyai kemiringan cukup besar untuk mengalirkan air secara gravitasi. Situasi ini dapat dilihat dari hasil foto gambar -1 berikut:
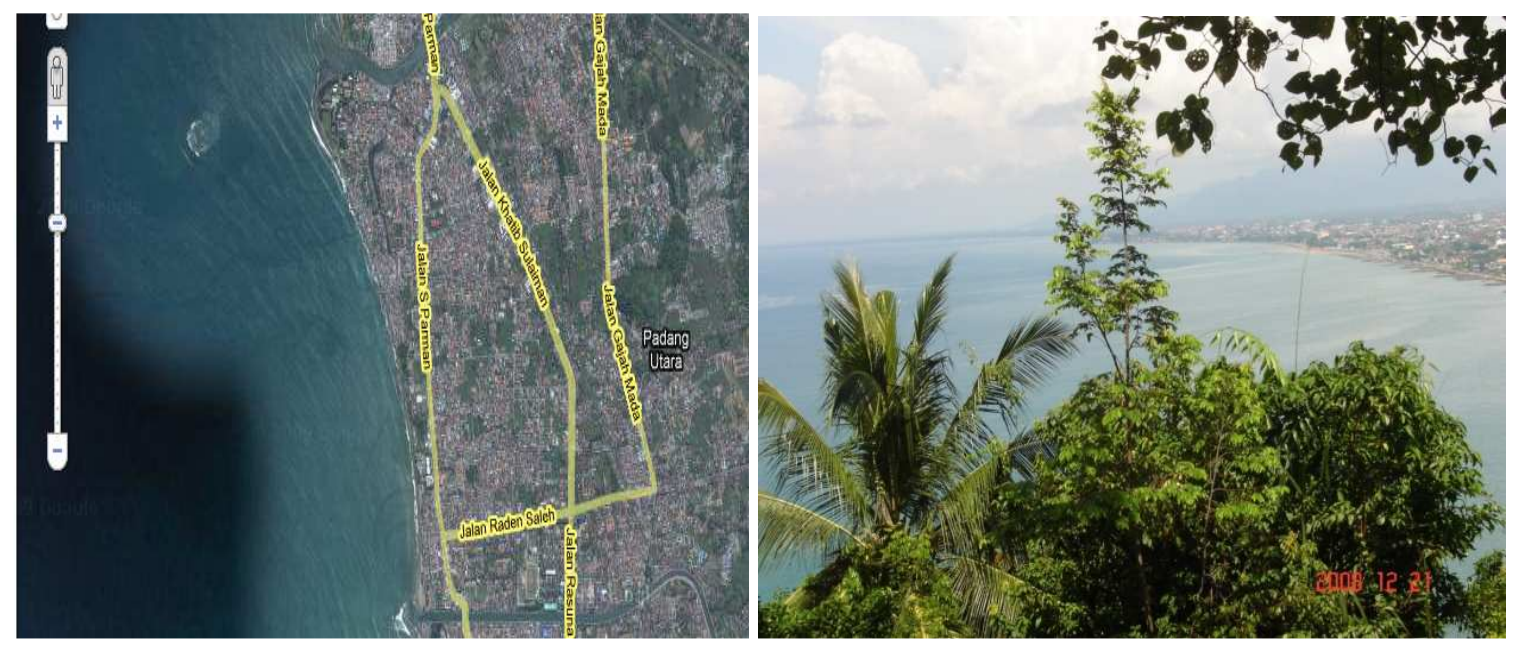

Gambar - 1. Lokasi Kajian Pantai Purus hingga UlaK Karang Padang Utara

Model disimulasikan untuk dapat menggambarkan dan mempreridiksi daerah yang aman dilalui, serta besarnya genangan bila terjadi tsunami.Sehingga dapat dilakukan antisipasi dan mengurangi risiko. Model simulasi dengan beberapa batasan masalah yang perlu diperhatikan, yaitu:

1. Lokasi penelitian dari pantai Purus hingga pantai Ulak Karang dengan batas alamiah Batang Kuranji dan Bandar Bekali. 
2. Lokasi dari pantai hingga jalan Khatib Sulaiman, mewakili daerah pinggiran pantai sejauh lebih kurang $1,0 \mathrm{~km}$. dari pantai.

3. Model disederhanakan dengan skala vertikal1 : 400, horizontal 1:1500 dan mempertahankan infrastruktur, yaitu jalan raya, jalan lingkungan dan saluran drainase atau sungai.

4. Bangunan diantara jalan dibuat masif dan segiempat.

5. Gelombang tsunami dibangkitkan berupa gelombang tunggal.

6. Kemiringan lokasi penelitian dianggap datar, karena kenaikannya relatif kecil.

\section{TINJAUAN PUSTAKA}

\subsection{Potensi Gempa dan Tsunami}
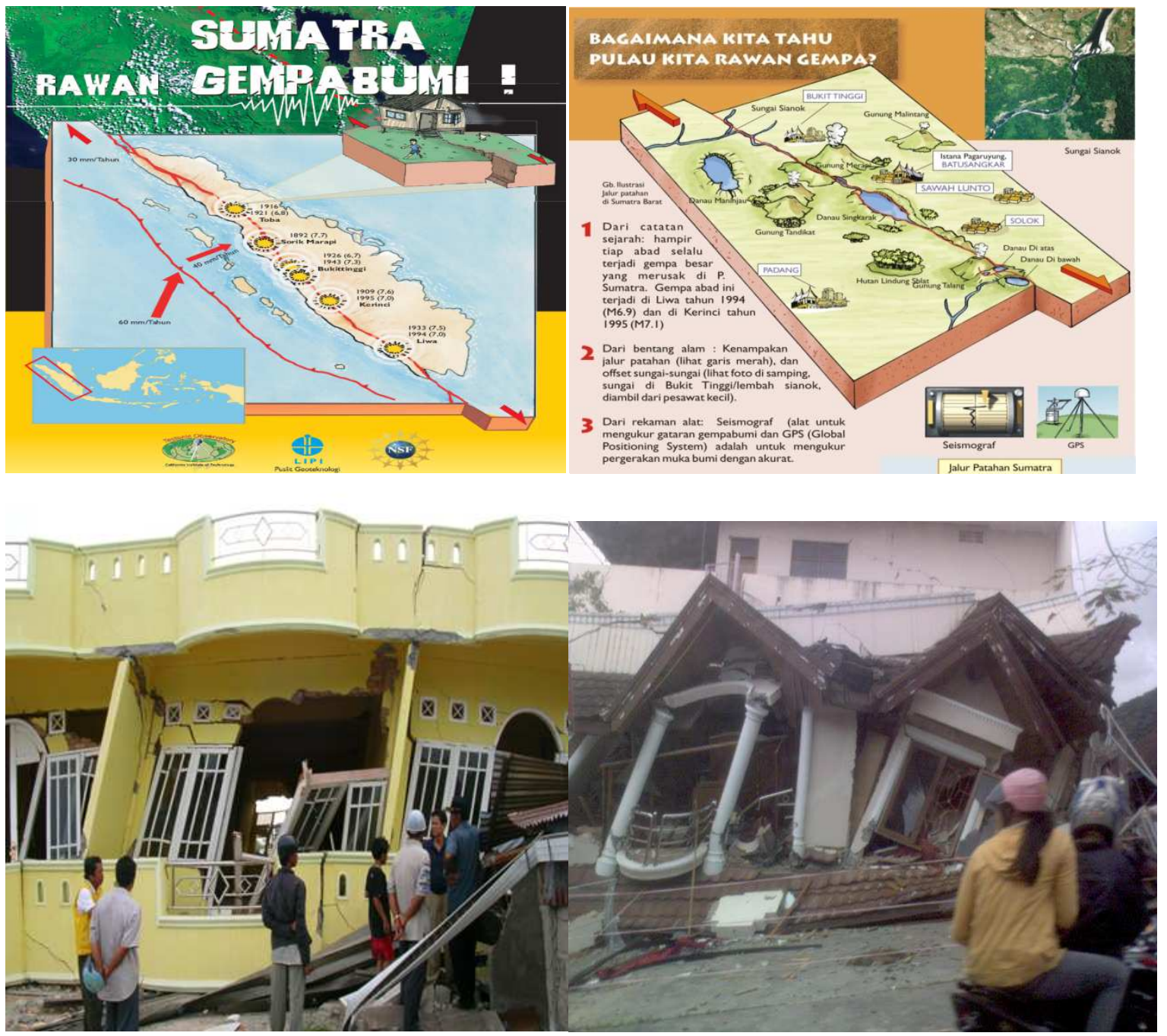

Gambar - 3 Dampak Gempa 2007 dan 2009,Ruko dan Hotel Ambacangdi Kota Padang

Pulau Sumatera yang membentang dari Utara hingga Selatan merupakan pulau yang memiliki beberapa sesar (patahan). Sesar tersebut melalui daratan, yakni sekitar Bukit Barisan dan di lautan dekat kepulauan Mentawai. Dua sesar ini sangat berpotensi untuk menjadikan goncangan atau disebut gempa (earthquake) yang akan memberikan dampak baik pada daratan maupun di laut. Untuk kasus di laut dapat saja menimbulkan gelombang besar atau dikenal dengan gelombang 
tsunami.Gambar berikut menunjukan pusat gempa di pulau Sumatera, semuanya berada pada Bukit Barisan.Sedangkan potensi gempa di Sumbar dapat di lihat gambar disampingnya.

\subsection{Terjadinya Tsunami}

Tsunami adalah istilah dalam bahasa Jepang yang pada dasarnya menyatakan suatu gelombang laut yang terjadi akibat gempa bumi tektonik di dasar laut. Magnitudo Tsunami yang terjadi di Indonesia berkisar antara 1,5-4,5 skala Imamura, dengan tinggi gelombang Tsunami maksimum yang mencapai pantai berkisar antara 4 - 24 meter dan jangkauan gelombang ke daratan berkisar antara 50 sampai 200 meter dari garis pantai.

Berdasarkan Katalog gempa (1629 - 2002) di Indonesia pernah terjadi tsunami sebanyak 109 kali , yakni 1 kali akibat longsoran (landslide), 9 kali akibat gunung berapi dan 98 kali akibat gempa bumi tektonik.

Kemungkinan tsunami di daerah Sumatera Barat khususnya kota Padang telah dipetakan oleh tim ahli kegempaan dan tsunami, seperti gambar 4 di bawah ini. Warna merah merupakan daerah rawan tsunami dan hijau daerah yang aman terhadap tsunami.

\subsection{Terjadinya Tsunami}
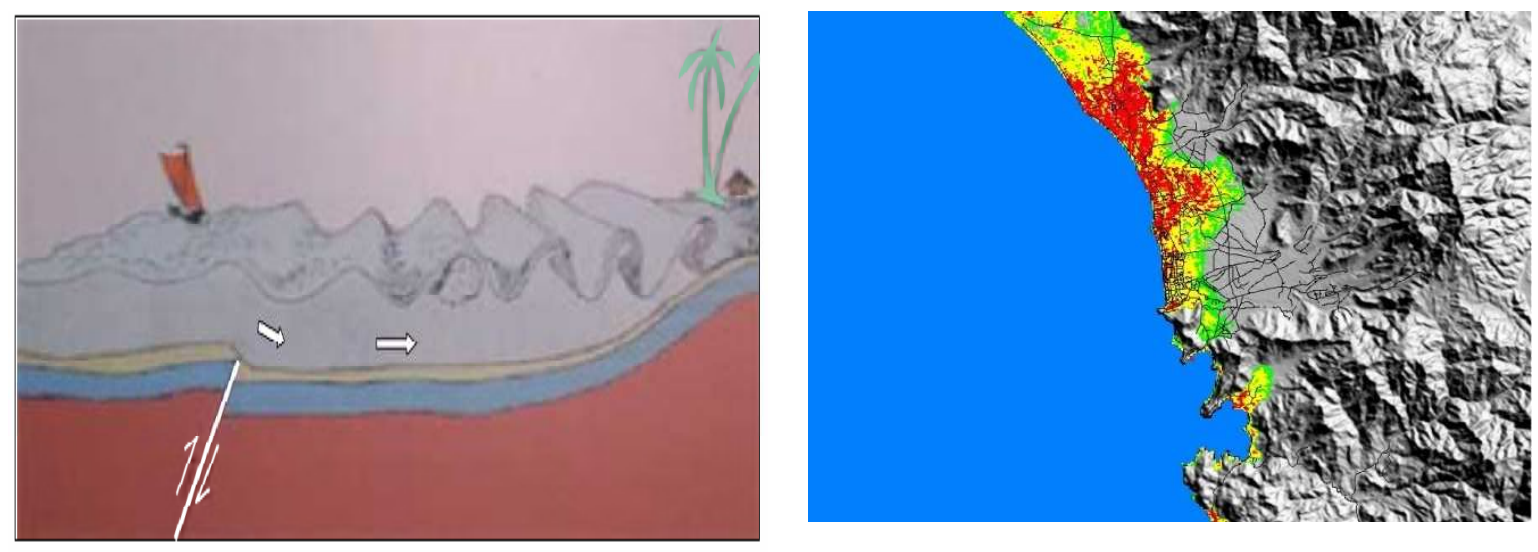

Gambar - 4 Model terbentuknya Gelombang Tsunami dan Daerah Rawan Gempa Kota Padang Blank (11pt)
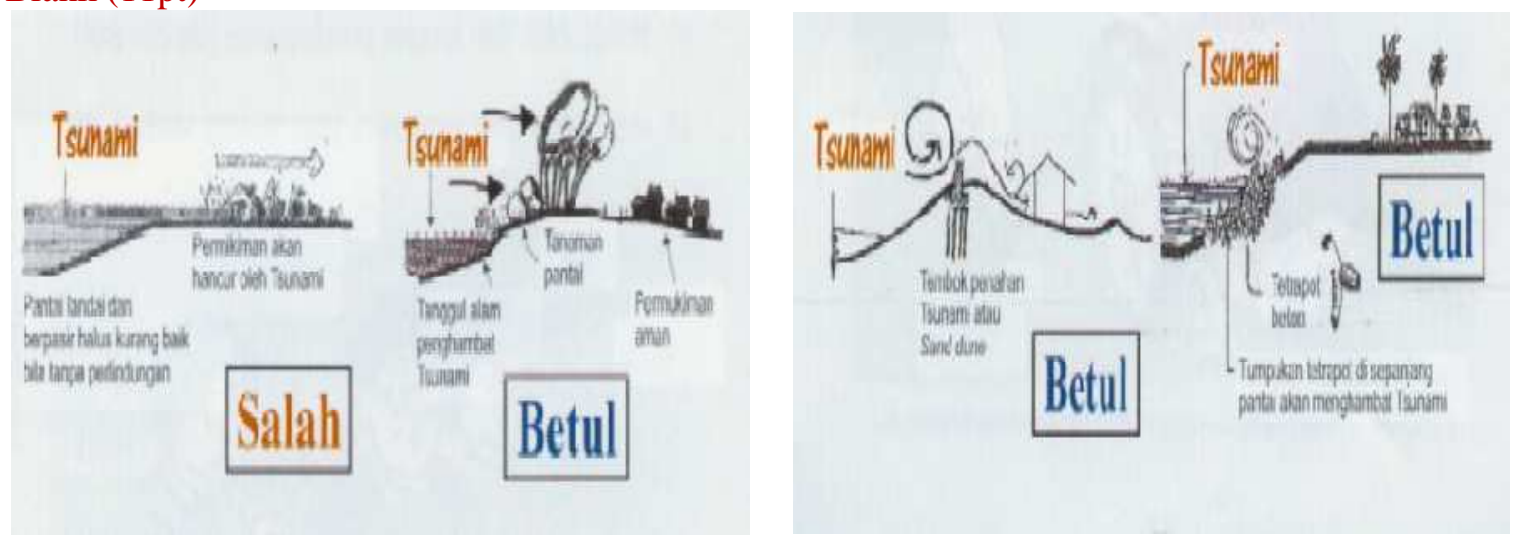

Gambar -5. Perlindungan Permukiman terhadap Bencana Gelombang Pasang Tsunami

Dampak Tsunami semakin intensif pada lingkungan yang mempunyai ciri dan bentuk pantai, tata letak bangunan sebagai berikut. Pantainya terletak di bagian teluk yang setengah tertutup, 
pantainya tidak ditumbuhi pepohonan yang cukup lebat ,pantainya tidak memiliki tanggul atau galengan penahan gelombang yang cukup tinggi, seperti gambar 5 .

\section{METODA PENELITIAN}

\subsection{Tahapan Penelitian}

Secara umum urutan penelitian diawali dengan dengan membuat model fisik sebagai bentuk tiruan terhadap kondisi sebenarnya. Melalui model ini akan dilakukan beberapa perlakuan terhadap tinggi gelombang dan besarnya energi yang dilepaskan. Meskipun begitu model yidak dapat dibuat begitu saja.Dimana perlu penelitian awal agar model dapat dibuat. Untuk itu ada beberapa kegiatan yang harus dilakukan sebagai berikut:

1. Melakukan kajian terhadap literature yang telah dipublikasikan dan diperoleh beberapa dasar untuk membuat model.

2. Melakukan survey dan pembacaan terhadap peta topografi yang menunjukan lokasi kajian di lapangan. Kegiatan ini diamati melalui peta yang ada dan dicoba mengelompokan dan menentukan batasan daerah lokasi penelitian.

3. Melakukan pengukuran ulang terhadap tempat tempat yang dominan pengaruhnya (asumsi awal) sebagai daerah genangan yang mungkin terjadi, seperti jalan raya (jalur evakuasi) dan kolam tampungan banjir sementara dan lahan terbuka.

4. Melakukan survey terhadap bangunan sarana dan prasarana, yakni gedung, jalan raya jalan , dan jembatan. Gedung dilakukan survey terhadp bangunan bertingkat 2 dan 3 dan seterusnya.

5. Merancang peletakan model (meja model), pembangkit gelombang tanki penampungan dan alat ukur tinggi genangan. Model didesain untuk dapat mensimulasikan gelombang dengan debit dan tinggi jatuhan yang bervariasi. Kemudian hasil rancangan dibuat dibengkel (workshop).

6. Membuat model fisik dengan skala laboratorium. Pelaksanaan ini membutuhkan ketelitian agar kondisi lapangan dapat terwakili dengan model tiruan. Model dibuat melalui beberapa bagian yang dibuat sedekat mungkin dengan kondisi, dimana jalan dan saluran diutamakan. Sedangkan rumah tinggal dan gedung lainnya dibuat perblok dan dianggap ketinggiannya sama tinggi.

\subsection{Pembuatan Model Fisik}

Setelah melakukan kegiatan 1 hingga 5 di atas, maka dirancanglah model.Pertama-tama peta lokasi (dari hasil foto udara), dilakukan pembesaran sesuai skala (asumsi skala 1: 40) yang diinginkan dan penyesuaian dengan kemampuan alat (meja model).Selanjutnya gambar dicetak pada kertas foto dan dilaminasi hingga mampu tahan terhadap air. Adapun rangkaian kegiatannya sebagai berikut:

a. Gambar dilukiskan pada acrylic (plastic transparan), sehingga dapat dilukiskan jalan, gedung, kolam atau saluran yang dominanan untuk mewakili kondisi sebenarnya. Pelukisan perlu kehati- hatian agar model baik.

b. Penempelan model gedung, jalan dan saluran serta tanah lapangan pad acrylic, dan pemberian warna gedung. Warna untuk membedakan lokasi.

c. Pemeriksaan terhadap model dengan gambar sebenarnya dilakukan berulangkali, agar model mendekati sebanarnya, terutama pada jalan raya dan slauran (drainase), sungai (kali).

d. Lokasi penelitian tahap pertama dari pinggir pantai hingga jalan Rasuna Said untuk daerah Purus. Tahap selanjutnya akan dipakai untuk daerah Lolong dan Ulak Karang (pengamatan difokuskan pada Jalan Rasuna Said hingga Sulaiman). Ini berdasarkan 
informasi dari peta jalur evakuasi bencana, merupakan daerah tidak aman terhadap tsunami (merah).

\subsection{Pembuatan Meja Model}

Meja model adalah meja yang dipersiapkan untuk melakukan penelitian dengan skala lab.Alat ini dibuat dengan ukuran $120 \times 240 \times 40 \mathrm{~cm}$. Dilengkapi dengan tanki pembangkit gelombang deengan ukuran $120 \times 80 \times 40 \mathrm{~cm}$ dan tanki penampungan air $80 \times 120 \times 50 \mathrm{~cm}$. Untuk memudahkan pengamatan meja model dan alat pembangkit ditinggikan dengan kaki meja setinggi $75 \mathrm{~cm}$.

\subsection{4Prosedur Penelitian}

Sebelum pengujian perlu dilakukan persiapan, yakni membersihkan meja model dan mengisi air setinggi yang diinginkan. Kemudian mengatur tinggi meja model agar dapat diamati, selanjutnya dapat diikuti langkah pengujian seperti berikut ini:

a. Persiapan pengujian, yakni semua alat dibersihkan dan dirapikan

b. Meletakan model di atas meja model dan di buat fixed di tengah meja model. Model dibagi menjadi beberapa blok. Hal ini dilakukan agar skala model lebih besar dan mudah diamati pengalirannya.

c. Setelah itu diisikan air ke tanki pembangkit ketinggian minimum hingga maksimum.(yakni dibagi tiga variasi).

d. Kemudian tanki pembangkit diangkat setinggi yang diinginkan, sehingga menimbulkan gelombang air dengan menjatuhkannya tiba-tiba.

e. Gelombang yang merambat diamati hingga menabrak model dan sambil diamati arah aliran air terutama pada jalan dan saluran drainase.

f. Kemudian diamati bangunan mana saja yang tenggelam dan bagian yang tidak tenggelam serta kerusakan yang terjadi.

g. Mengukur tinggi air di jalan, drainase dan lapangan serta luas genangannya.

h. Semua dibuat dokumentasinya dan film setiap pergantian dan running.

i. Setelah itu dilakukan untuk tinggi jatuhan yang lainnya, sampai tinggi maksimum yang diinginkan.

j. Apabila langkah -3 hingga -9 telah selesai dilakukan untuk satu model, maka diulangi untuk model lainnya.

\section{HASIL DAN PEMBAHASAN}

\subsection{Lama Waktu Tempuh pada Jalur Evakuasi}

Berdasarkan hasil wawancara dengan masyarakat yang mengalami gempa pada 30 September 2009 di kawasan pantai Ulak Karang dan Purus. Jaluryang dilalui adalah jalan Paus-Simpang Pasar Ulak Karang -Joni Anwar dan berakhir di pertigaan Naggalo (Simpang Tinju). Hampir semua responden mengalami waktu tempuh rata-rata 60 menit untuk panjang jalan 2,502 km, atau kecepatan rata-rata $2,5 / 60 / 60 \mathrm{~km} / \mathrm{jam}=2,5 \mathrm{~km} / \mathrm{jam}$. Kondisi saat itu masyarakat tumpah ruah ke jalan dan yang menggunakan kendaraan berpacu dengan pejalan kaki, sehingga ruang untuk pejalan kaki semakin sempit.

Hasil wawancara untuk daerah Purus lebih baik dibandingkan dengan daerah Ulak Karang, yaitu rata-rata 20 - 25 menit, walaupun panjang jalan sedikit lebih panjang dari Ulak Karang, yakni 2,5 $\mathrm{km}$. Jadi kecepatan tempuh rata-rata $2,5 / 20 \mathrm{~m} / 60 \mathrm{~m}$ adalah $7,5 \mathrm{~km} / \mathrm{jam}$. 


\subsection{Kondisi Genangan Setelah Dihantam Gelombang}

Gelombang dibangkitkan sedemikian rupa sehingga mewakili kondisi yang sebenarnya, yakni air surut dan kemudian tumpah dalam jumlah yang besar.Diharapkan gelombang pecah di pantai.Besarnya energi gelombang yang ditimbulkan, diasumsikan berupa perubahan energi potensial ke energi kinetis.Terlihat bahwa dari hasil percobaan bahwa air mengalir ke darat lebih cepat melalui saluran dan jalan raya. Berikut gambar 8-10 adalah hasil pengujian dengan berbagai tinggi jatuh (Hi) dan tinggi gelombang awal mencapai pinggiran pantai (hi), digambarkan dalam berupa ketinggian (kontur) air mencapai daratan
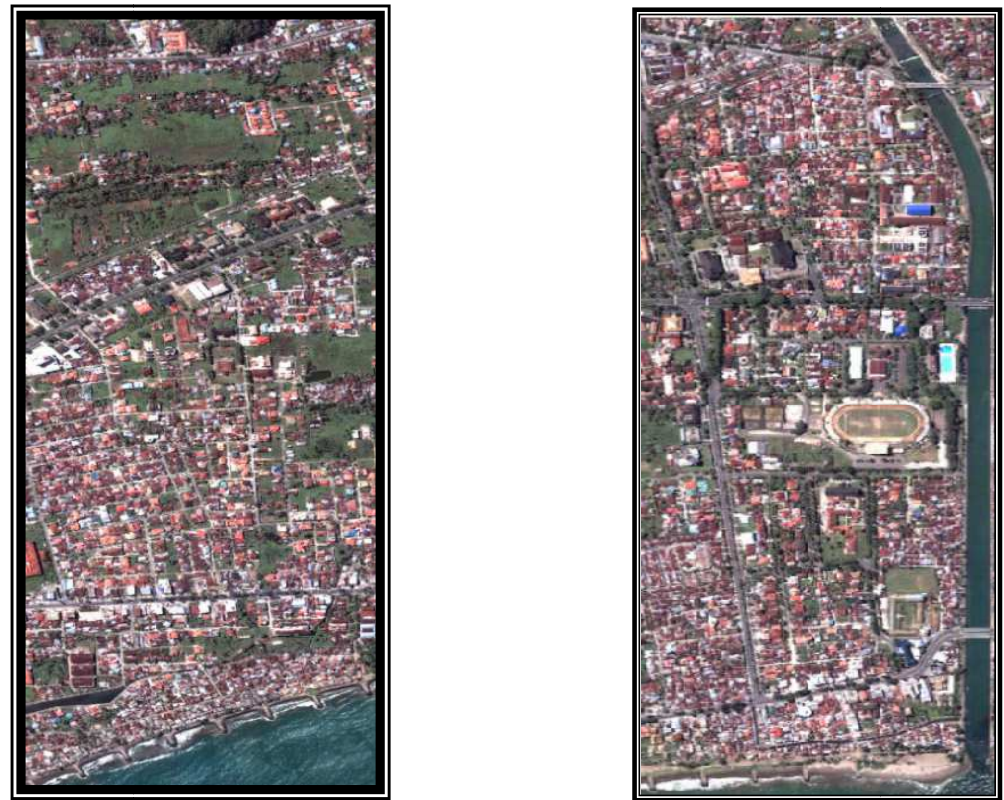

Gambar 6 Hasil Foto Udara Kawasan Ulak Karang dan Purus
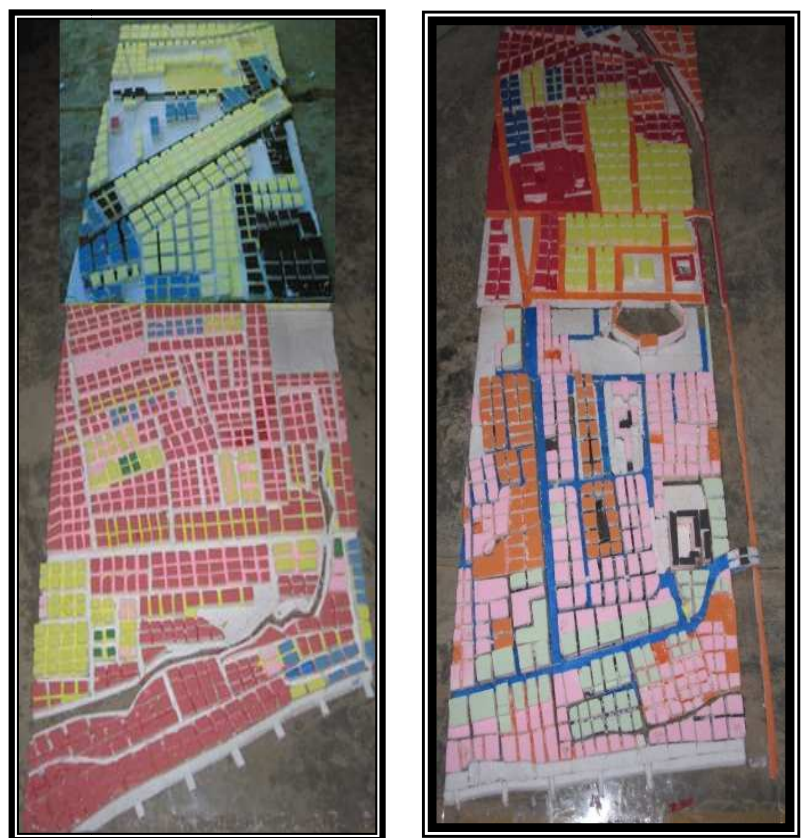

Gambar 6 Model Fisik KawasanUlak Karang dan Purus 

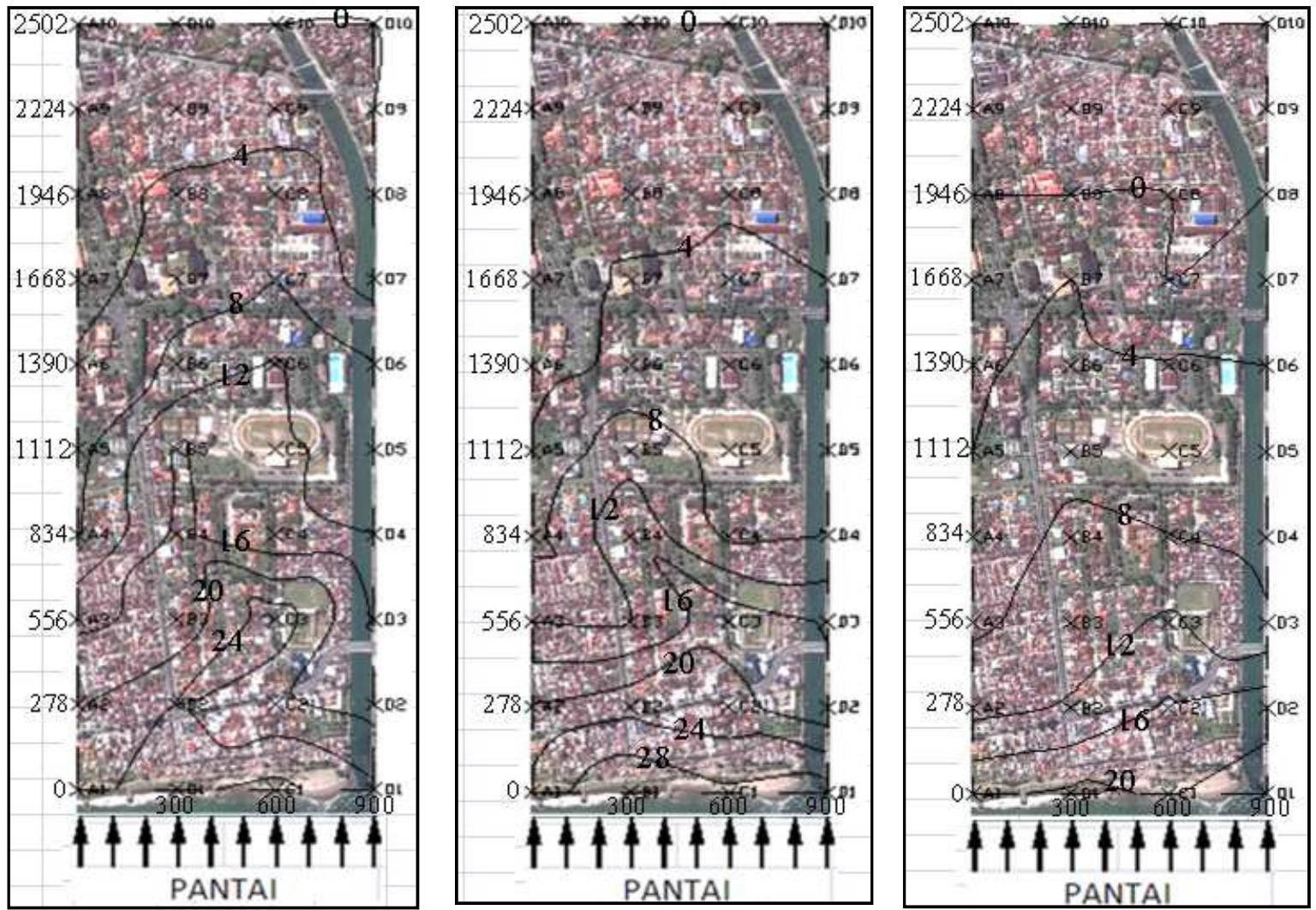

Gambar 8 KonturGenangan Air Daerah Purus dengan $\mathrm{H}=20 \mathrm{~cm}$ dan $\mathrm{h}=12,10$ dan $8 \mathrm{~cm}$;
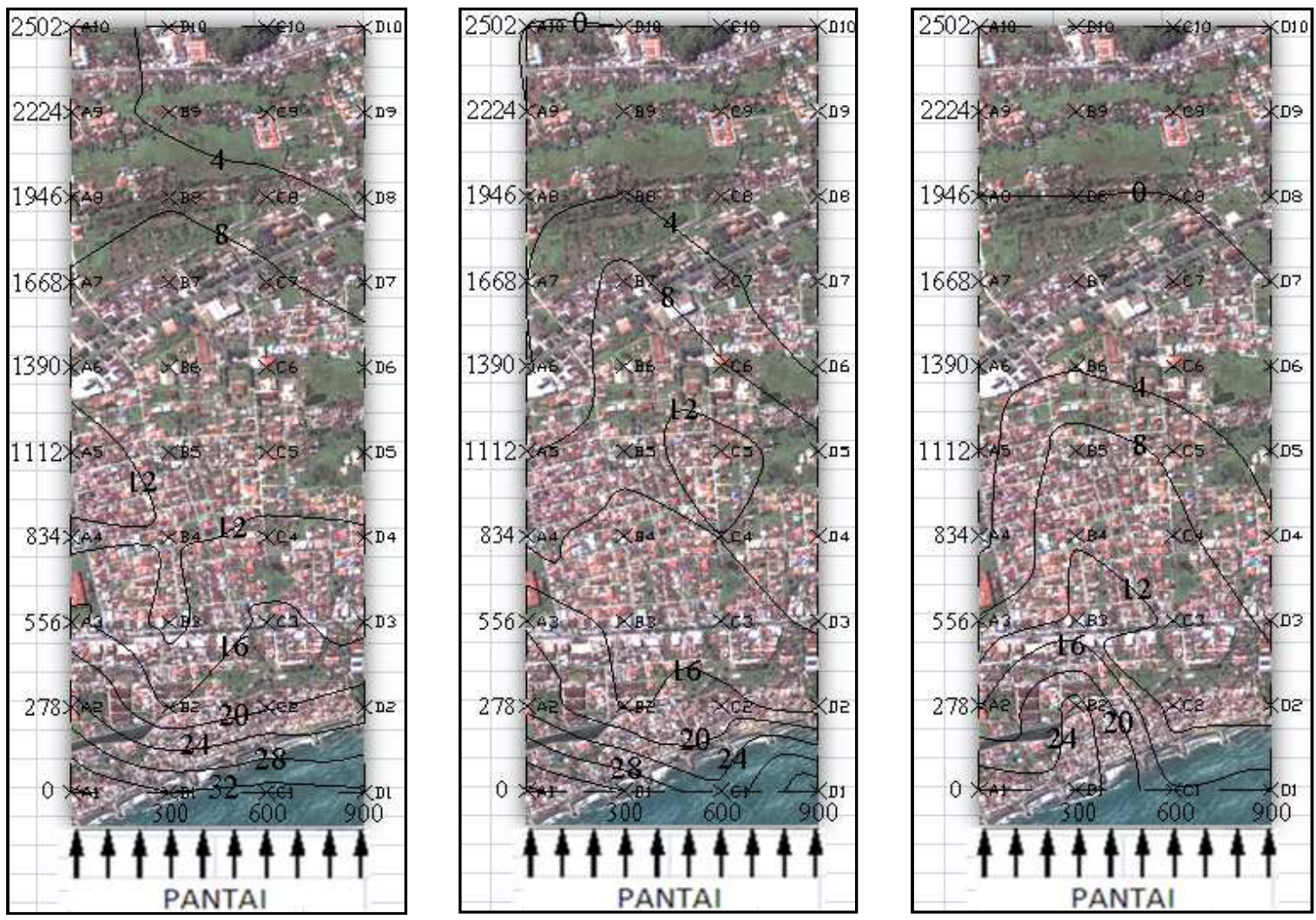

Gambar 9 KonturGenangan Air Daerah Purus dengan $\mathrm{H}=20 \mathrm{~cm}$ dan $\mathrm{h}=12,10$ dan $8 \mathrm{~cm}$ 


\subsection{Pembahasan}

\subsubsection{Waktu Tempuh}

Terlihat dari survey, bahwa waktu tempuh untuk daerah Ulak Karang cukup lama, dimana melebihi dari kecepatan normal pejalan kaki dewasa adalah $5 \mathrm{~km} / \mathrm{jam}$. Tetapi untuk daerah Purus sudah melebihi dari kecepatan normal. Hal ini dapat dipahami karena kondisi jalan di Ulak Karang lebih sempit ( jalan dua jalur dua arah) dibanding dengan di Purus (jalan Raden Saleh dua arah atau empat jalur). Disamping saat itu masyarakat tumpah ruah ke jalan dan yang menggunakan kendaraan berpacu dengan pejalan kaki, sehingga ruang untuk pejalan kaki semakin sempit.Kondisi initentu jauh dari kondisi normal untuk pejalan kaki,dimana waktu tempuh, yakni 30 - 40 menit dengan kecepatan sekitar 3,5 - 5 km/jam.

Bila dicermati hasil perhitungan waktu tempuh terlihat daerah Purus lebih baik daripada daerah Ulak Karang, akan tetapi bila di amati dari kecepatan gelombang tsunami lebih dari $100 \mathrm{~km} / \mathrm{jam}$ di daerah pusat gempa. Dengan asumsi kecepatan di pantai $10-20 \mathrm{~km} / \mathrm{jam}$ maka waktu tempuh diperlukan untuk jarak 2,5 km adalah 2,5km/10 km/jam adalah 15 menit. Untuk kecepatan 20 $\mathrm{km} / \mathrm{jam}$ adalah 7,5 menit.

Secara perhitungan lama waktu tempuh daerah Purus masih aman, tetapi berjalan di atas pengaruh arus air tentu akan menguras fisik dan menjadikan lebih lama. Artinya perlu diperhatikan bahwa jalur evakuasi terlalu panjang untuk sampai daerah aman. Disarankan untuk masyarakat pinggir pantai lebih baik mencari shelter yang terdekat dari pada menggunakan jalan raya.

\subsubsection{Arah Aliran dan Panjang Genangan}

\subsubsection{Arah Aliran}

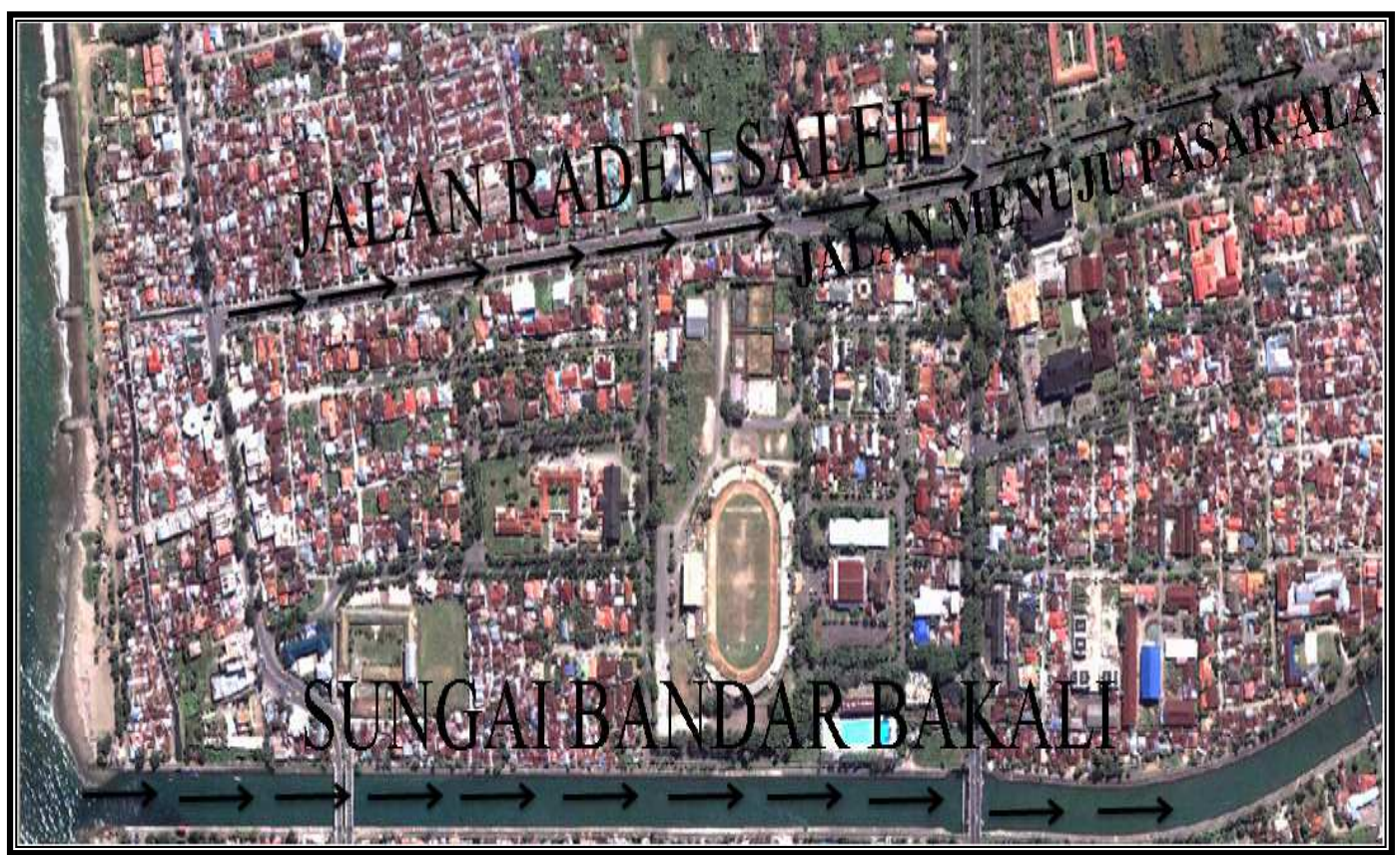

Gambar 10 Arah Aliran Dominan Terjadi untuk Setiap Pengujian

Dari hasil pengamatan dan gambar kontur kedalaman air di atas diperoleh bahwa kedalaman genangan lebih cepat terjadi pada daerah jalan raya dan di drainase (banjir kanal). Dimana kontur 
kedalaman lebih dalam pada jarak yang sama dari pinggir pantai atau lebih jauh dari pantai dibandingkan dengan daerah padat bangunan (rumah atau rumah toko dua lantai) dengan kedalaman yang sama. Gambar 10 menunjukan arah aliran secara umum dan dominan. Untuk arah lainnya relatif kecik dan arahnya mengikuti jalan lingkungan yang ada.

\subsubsection{Panjang Genangan}

Genangan akan semakin panjang terjadi akibat besarnya energi yang akan mendorong atau $(\mathrm{H})$ lebih besar untuk massa air yang sama. Dari gambar kontur air di atas terlihat, bahwa kedalaman 4 $\mathrm{m}$ semakin ke arah Timur atau menjauhi pantai. Artinya semakin panjang daerah yang akan tenggelam dengan massa air yang sama, maka luasdaerah yang terendam semakin besar. Sebagai hasil percobaan lainnya untuk tinggi gelombang di pantai (h) adalah $8 \mathrm{~cm}$ atau 32 meter skala lapangan akan mengakibatkan genangan paling jauh 2,5 km. Gambar -11 dan 12 di bawah ini menunjukan hubungan jarak genangan dengan kedalaman air atau tinggi genagan. Terlihat bahwa genangan semakin tinggi dengan tinggi gelombang (h) semakin besar.

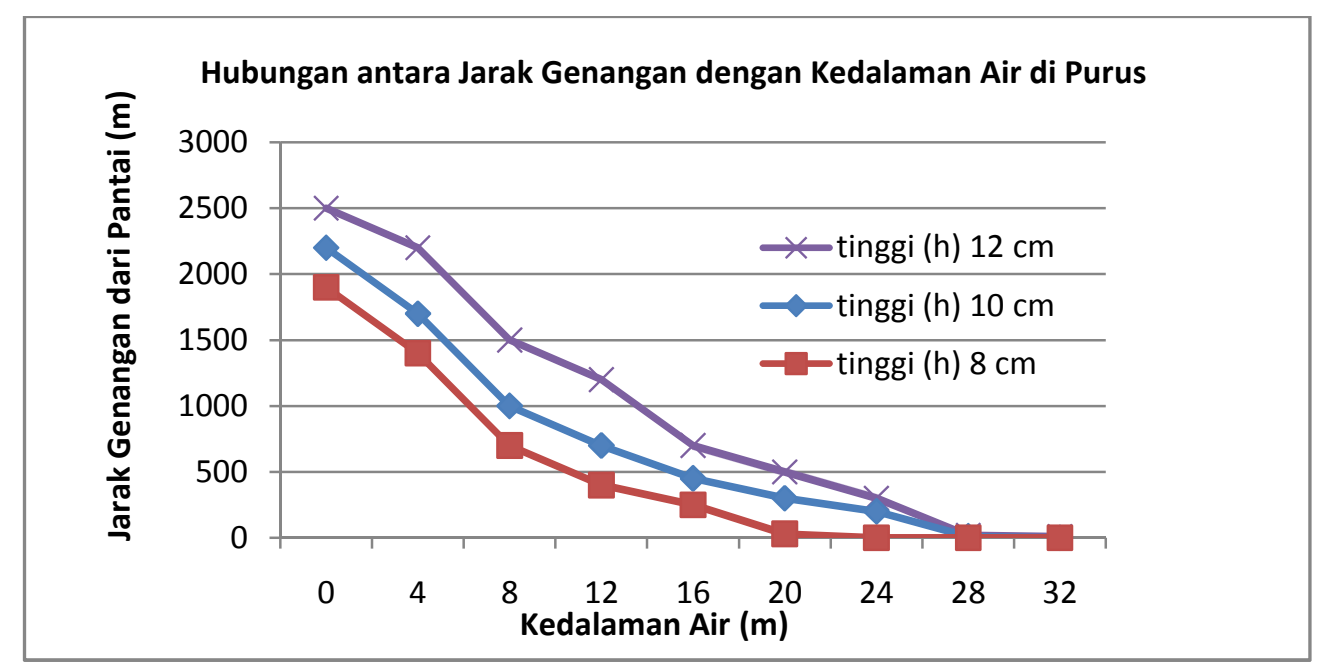

Gambar 11 Hubungan antara Jarak Genangan dari Pinggir Pantai Purus

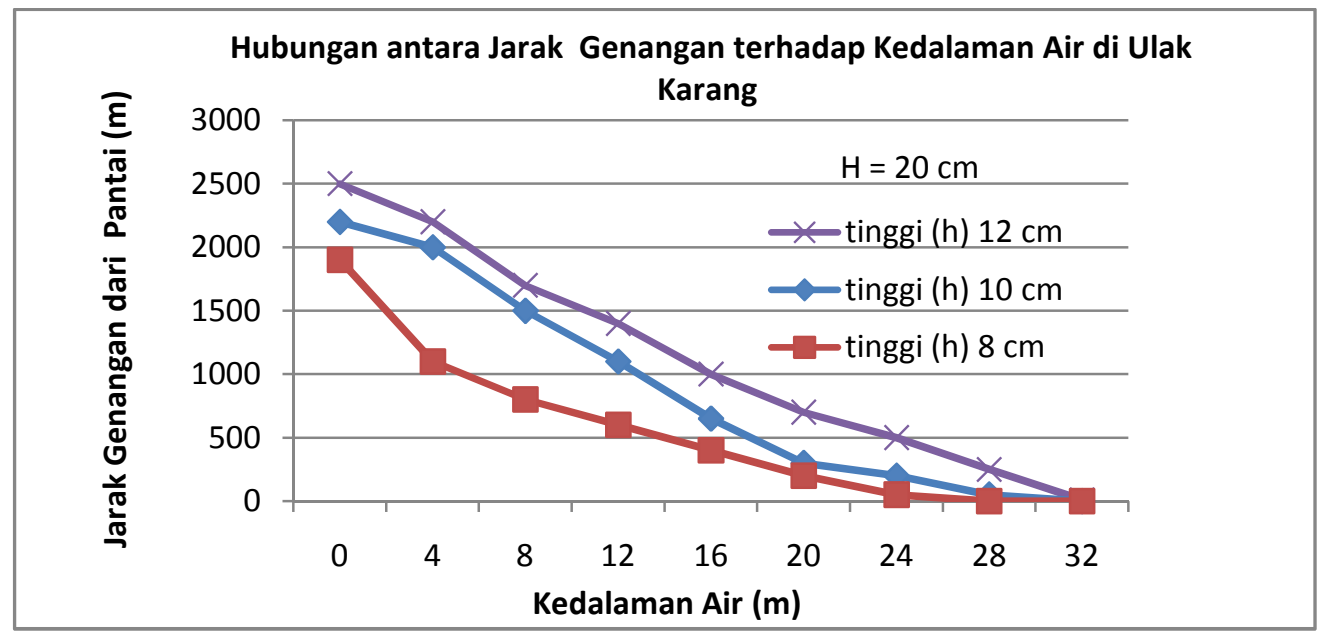

Gambar 12 Hubungan antara Jarak Genangan dari Pinggir Pantai Ulak Karang

Sebagai alternatif untuk penelitian ke depan, maka perlu dibuat bangunan penghambat gelombang. Dalam arti kata rambatan gelombang dengan waktu yang cukup lama dan tinggi genangan 
diturunkan. Bentuk penanganan dapat dilakukan dengan membuat bangunan tinggi sepanjang pantai, membuat kanal sepanjang pantai atau membuat breakwater agar gelombang pecah ditengah laut sebelum sampai ke pantai. Bangunan ini dapat dibuat tersendiri atau gabungan dari masingmasingnya. Penelitian lebih lanjut akan dilakukan dengan meredam besarnya gelombang sampai ke pantai.

\section{KESIMPULAN}

Dari hasil perlakuan terhadap model eksisting dapat disimpulkan dan direkomendasikan sebagai berikut.

1. Jalur evakuasi dapat dilalui untuk gelombang kecil, sebaliknya untuk gelombang besar perlu perhatian khusus, karena genangan cukup tinggi.

2. Untuk gelombang besar semua daerah digenangi oleh air, hingga jalan Rasuna Said dan Khatib Sulaiman.

3. Daerah pada lokasi setelah jalan Khatib Sulaiman dan Rasuna Saidcukup aman untuk gelombang kecil tetapi untuk gelombang sedang dan bear tidak aman.

4. Disarankan perlu dilakukan penelitian lebih lanjut tentang bangunan yang dapat meredam energi dan memperlambat penjalarannya. Serta perlu antisipasi terhadap arus balik, dimana kekuatannya cukup besar menghanyutkan benda-benda yang ada.

Blank (11pt)

Blank (11pt)

\section{DAFTAR KEPUSTAKAAN}

Blank (11pt)

1. Daoed, D., (2010) Model Simulasi terhadap Dampak Gelombang Besar (Tsunami) pada Daerah Sepanjang Pantai Kota Padang, Laporan Hasil Penelitian dibiayai OlehDikti, Kemdikbud, HSN 2009/2010

2. Daoed, D.,(2007) Suatu Konsep Sistem Pengendalian Banjir Kota Padang sehubungan dengan Tingkat Perkembangan Kota dan Topografi, Jurnal Rekayasa Sipil vol 3 No. 1.

3. Daoed, D.,(2007), Penelusuran Debit Banjir Secara Hidrologi (Study Kasus Pada Waduk PLTA Koto Panjang), Jurnal Rekayasa Sipil Vol 3 No. 2.

4. Daoed, D., Hadie M.S. Junaidi (2008), Pengaruh Superelevasi Tikungan Terhadap Pola Penyebaran Sedimen Laporan Hasil Penelitian dibiayai oleh, Dikti Dep. Diknas. Peneltitan Fundamental 2008/2009.

5. Daoed, Hadie M.S., Junaidi (2006) Pengaruh Variasi Geometrik Tikungan Terhadap Karakteristik Penyebaran Sedimen dan Pembentukan Lapisan Armouring di Dasar Saluran. Laporan Hasil Penelitian dibiayai oleh Dikti Dep.Diknas Penelitian Fundamental 2006/2007)

6. Operasionalisasi Program Penanganan Bencana Alam Bidang Penataan Ruang, web site Penanggulangan Bencana 2007.

7. Robert Kodoatie, 2002 Banjir (Beberapa penyebab dan Pengendalian) Pustaka Pelajar. 